\title{
Erosion and sediment transport processes in Mediterranean mountain basins
}

\author{
S. Beguería \\ Estación Experimental de Aula Dei - CSIC, Zaragoza, Spain \\ N. Lana-Renault, D. Regüés, E. Nadal-Romero, P. Serrano-Muela \& J.M. García-Ruiz \\ Instituto Pirenaico de Ecología - CSIC, Zaragoza, Spain
}

\begin{abstract}
Soil erosion and sediment production is a major environmental problem in the World, and especially in Mediterranean countries which are characterized by a harsh climate and a historical human pressure on the land. In a context of current and foreseen climate and land use change, our ability to predict the effects of these changes on soil erosion and on water quantity and quality become of great importance. A significant research effort has been made on the subject in the last two or three decades, based both in empirical observations from experimental field setups or in the use of simulation models. However, our understanding of some key processes is still poor, especially under a multi-scale perspective. This encourages the need for further empirical and modelling studies. In this paper, a review of the problem is made and some results are shown from studies in the Spanish Pyrenees. These results are followed by a discussion of several important research questions regarding the use of field experiments and simulation models.
\end{abstract}

\section{INTRODUCTION}

Soil erosion by water is currently considered one of the main environmental problems in subhumid and semi-arid environments of the World, threatening the quality of life and the survival of millions of people. Erosion and desertification are responsible for large population movements in some countries, which cause political, social and economical instability at national and international scales (Puigdefábregas and Mendizábal, 1995). In the case of Mediterranean countries, soil erosion has been identified as a major problem (Poesen and Hooke, 1997), resulting in changes in soil characteristics, loss of productivity, reservoir siltation and changes in the quantity and quality of water resources (García-Ruiz and Valero-Garcés, 1998). Ultimately, soil erosion can cause a loss of biodiversity and welfare.

Obviously, most of these erosion-derived problems affect directly the areas where erosion occurs, but others, such as changes in fluvial channel dynamics, flood hazard and development of alluvial fans and deltas, can affect territories located far away. This is particularly the case of Mediterranean environments in which dramatic contrasts exist between the highlands and the lowlands, the former behaving as "islands" of humidity where most of water resources are generated, whereas most of the population and economic activities are located in the latter. Climate and land use change in these spatially restricted areas would disturb significantly the hydrological cycle, affecting water availability, flooding, and sediment transport in a much bigger area. For this reason, soil erosion can be considered a global problem, the causes and solutions of which being very complex and needing political and social implications, as well as deep changes in the perspective of land management. 
Studies on soil erosion in Mediterranean countries underwent an important push during the 1980's, and many research groups and projects appeared particularly in Spain but also in Israel, France and Italy and, to a lesser extent, in Greece, Turkey and the North of Africa. Nevertheless, some signs of stagnation are the more and more evident. The specialists are able to analyse in detail the processes, to deepen into the soil and rain drop characteristics, to improve the field and laboratory instruments, but our understanding of soil erosion as a global process is not improving: Our body of knowledge is basically the same than it was twenty years ago. Some errors from the past continue existing in the present-(e.g., the use of erosion rates, the comparison of results from different methods or from different scales-, and a holistic approach is increasingly needed to understand the spatial and temporal organisation of soil erosion and sediment delivery problems. Time has shown the importance of both empirical and simulation approaches to the problem of erosion and sediment transport, but an effort needs to be made to link together the processes acting at various temporal and spatial scales. Only that would allow us to answer current questions such as the relative importance of climate and land use practices on soil erosion, or evaluate global change scenarios with the purpose of land planning.

\section{EROSION AND SEDIMENT TRANSPORT AS A CHRONIC ENVIRONMENTAL PROBLEM IN THE MEDITERRANEAN}

Soil erosion is a very old problem in the Mediterranean area. Geo-archaeological, palinological and sedimentological studies illustrate on the decrease in vegetation as human pressure increased. Geomorphic studies demonstrate that during the second half of the Holocene many hillslopes experienced accelerated erosion rates, and valleys were filled with sediment. This was the case, for example, in the Ebro Valley since the Neolithic (i.e., Peña et al., 1993). Erosion was so intense in the Ebro Valley in the last 4000 years that no in-situ remnants of pre-Bronze Age archaeological sites have been preserved (González-Sampériz and Sopena, 2002). In the Pyrenees, Montserrat (1992) studied a core of sediment in the Tramacastilla Lake which shows clear evidence of severe and generalized fires occurred 4000 and 900 years ago, followed immediately by increases in the sediment size and the rate of sedimentation - several orders of magnitude higher than before the fires. The development of the Ebro Delta since the Roman times is also a good example of the geological consequences of an increasing human pressure accompanied with deforestation, grazing and farming. The period of maximum deltaic progradation between the 15 and 19th centuries coincides with a general expansion of cereal crops and livestock in the Ebro basin (Maldonado, 1983). Nevertheless, in these examples and in many others in the Mediterranean it is still very difficult to discriminate the relative roles of human activities and climatic fluctuations. In a context of foreseen climate and land use changes, this is one of the main scientific problems we need to solve.

It is well known that soil erosion by water depends on the complex interaction of several factors, mainly climate, soil characteristics, bedrock, plant cover and land management. All these factors tend, in general, to encourage soil erosion in Mediterranean environments. Mediterranean climate is characterized by strong seasonal contrasts in temperature and precipitation, and by intense rainstorms in any season of the year, particularly in autumn and summer (White et al., 1997). Many soils tend to be fragile and easily erodible due to the poor organic matter content or to sealing and crusting processes caused by raindrop impact and aggregate breaking (Yaalon, 1997). This is especially evident over certain impervious bedrocks (marls, lutites), where regolith weathering is very rapid and intense as a consequence of freezing-thaw and wetting-drying processes (Regüés and Gallart, 2004; Nadal-Romero et al., 2007). Finally, land-use / plant cover changes have been defined as the main factor of desertification in Mediterranean environments (Kosmas et al., 1997), with higher influence on soil erosion than climate change, since they can occur in a few years or decades. For instance, the substitution of forests or dense scrubland by cereal fields represents: i) an increase of rainfall that arrives directly to the soil, owing to the absence of interception; ii) a direct impact of raindrops on the soil, thus favouring sealing, crusting and splash processes; iii) an increase of overland flow and sheet wash processes; iv) an expansion of runoff and sediment generating areas; v) a change in the frequency and magnitude of floods, reducing the return period for the same flood event; and vi) a rapid change in the hydrological functioning of the soils (infiltration rate, water storage, timing of 
wetting-drying processes). Similar changes occur if the scrubland is open by overgrazing or by periodical burning.

The consequences of these changes are also well known: increase in soil stoniness, elimination of the upper soil horizons, development of rills and, in the worst cases, gullies and badlands. These processes occur in both relatively wet and dry environments (Central and Eastern Pyrenees, and Southeast Spain and the Central Ebro basin, respectively). Many alluvial fans have been considered as a secondary effect of increased soil erosion (Gómez-Villar et al., 2006) due to their recent origin, as well as aggradation of alluvial plains and the development of braided channels (Beguería et al., 2006). Finally, reservoir siltation is a very serious problem for water resources management, since it reduces the capacity for water storage and shortens the useful lifetime of the dams. Some reservoirs have a sediment trap capacity close to $100 \%$, due to their large size in relation with the fluvial discharge (Almorox et al., 1994). The most important problems of reservoir siltation occur in semi-arid environments with occasional but very intense rainstorms, low plant cover density and presence of badlands in the basin, as it occurs in Southeast Spain. In general, badlands in marls and lutites are the main sediment sources (Beguería, 2005).

\section{METHODOLOGICAL APPROACHES TO THE PROBLEM OF EROSION AND SEDIMENT TRANSPORT: MANY POINTS OF VIEW FOR A SINGLE, MULTI- SCALING PROBLEM}

The processes of runoff generation, soil erosion and sediment delivery are characterized by a multi-scaling behavior, in which different process interplay at different spatial and temporal scales. Soil erosion and sedimentation have been studied by using a variety of methods and at several temporal and spatial scales. This is a huge problem when one tries to compare the information obtained from different sites. It is very important to understand that each method is related to certain research questions, which are necessarily different to those posed with other methods. Besides, in some cases, the use of certain methods is a consequence of the financial or personnel possibilities of a research group.

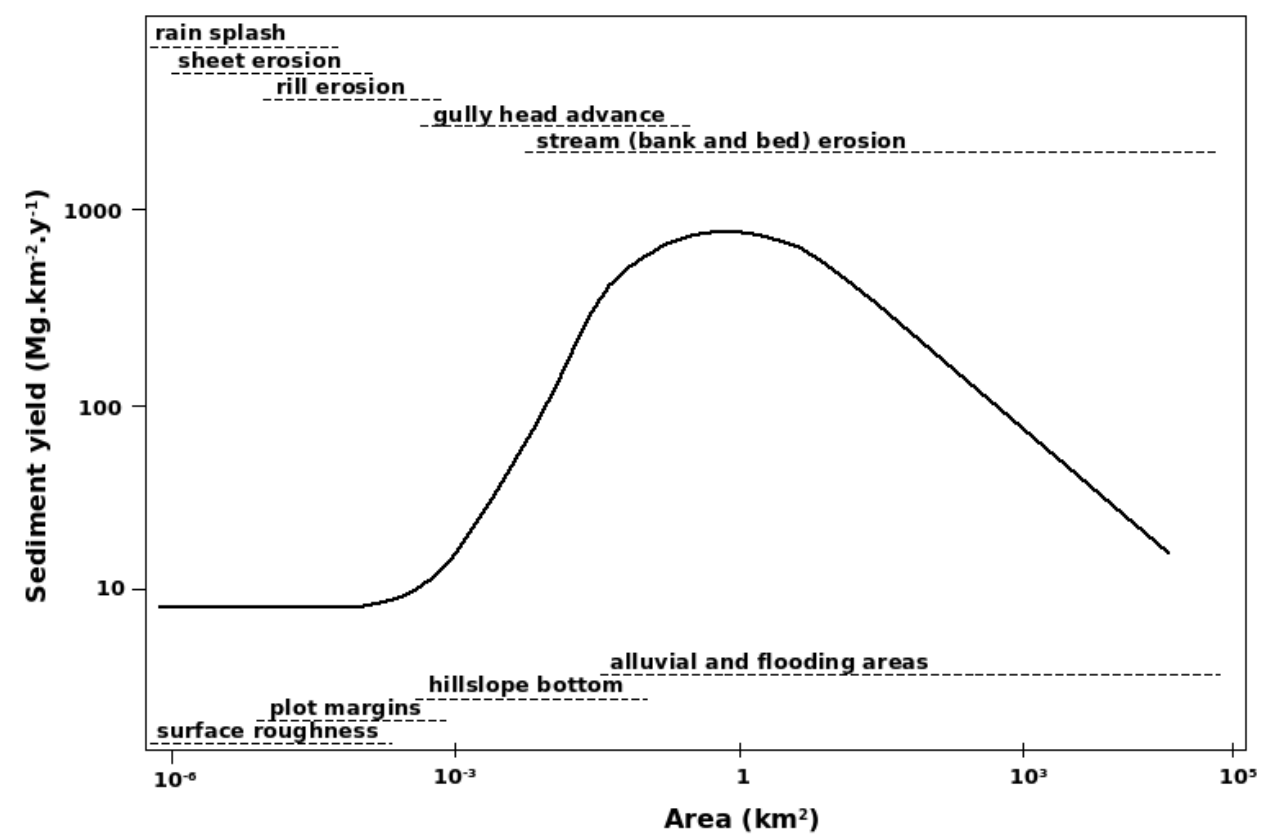

Figure 1. Variation of sediment yield with respect to the catchment size (conceptual sketch). Sediment yield at a given spatial scale depends on the interplay of several erosion processes, and different processes prevail at characteristic scales. Also, the role of the major sediment sinks (deposition areas) changes according to the size of the area of interest. The main erosion processes and sediment sinks are shown in the figure. 
A rapid summary of methods or techniques used in soil erosion studies includes piquettes and micro-topographic profilers, rainfall simulation (less than $1 \mathrm{~m} 2$, in most of cases), experimental plots (in general, lower than $100 \mathrm{~m} 2$ ), experimental catchments (few decades to hundreds of hectares), estimation of sediment siltation in reservoirs (bathimetric approach), radioisotope inventories (particularly 137Cs) and mapping erosive features by aerial photo interpretation and remote sensing -in parallel with Geographic Information Systems. Each of these approaches faces the study of soil erosion at a given characteristic scale. It is well know that different erosion and sediment transport processes prevail at different scales, what adds to the difficulties of making general conclusions out of a broad range of methodologies: How is it possible to compare erosion rates obtained from rainfall simulation and those from experimental catchments? As a general rule, a progressive decrease in water and sediment yield is expected as we move from small to large study areas (Figure 1). Nevertheless, even this general principle is not necessarily true in some cases, as it has been shown in a characteristic catchment in the Spanish Central Pyrenees (Figure 2).

Furthermore, there is another important problem. Even if erosion rates should be obtained from the same scale and with the same methods, are we sure about their significance as average values? As the analysis of data obtained from experimental plots and catchments has shown, runoff and sediment transport rates exhibit large inter-annual fluctuations in the Mediterranean, as a consequence of the highly varying characteristics of precipitation and temperature. It is well known that most of soil erosion and transport tends to occur during a few, intense rainstorm events. For instance, in badlands of the Ebro Depression, Desir (2000) demonstrated that erosion was reduced by one order of magnitude when the study period was increased from only some months to nine years. Likewise, in the Izas experimental catchment (upper Gállego Valley, Central Pyrenees) one single rainstorm in October 1987 yielded as much sediment as the total amount recorded during the next decade. The conclusion is that information on erosion rates is strictly comparable only when the same study period is used, imposing a severe constraint to comparative studies gathering data from many different sources.

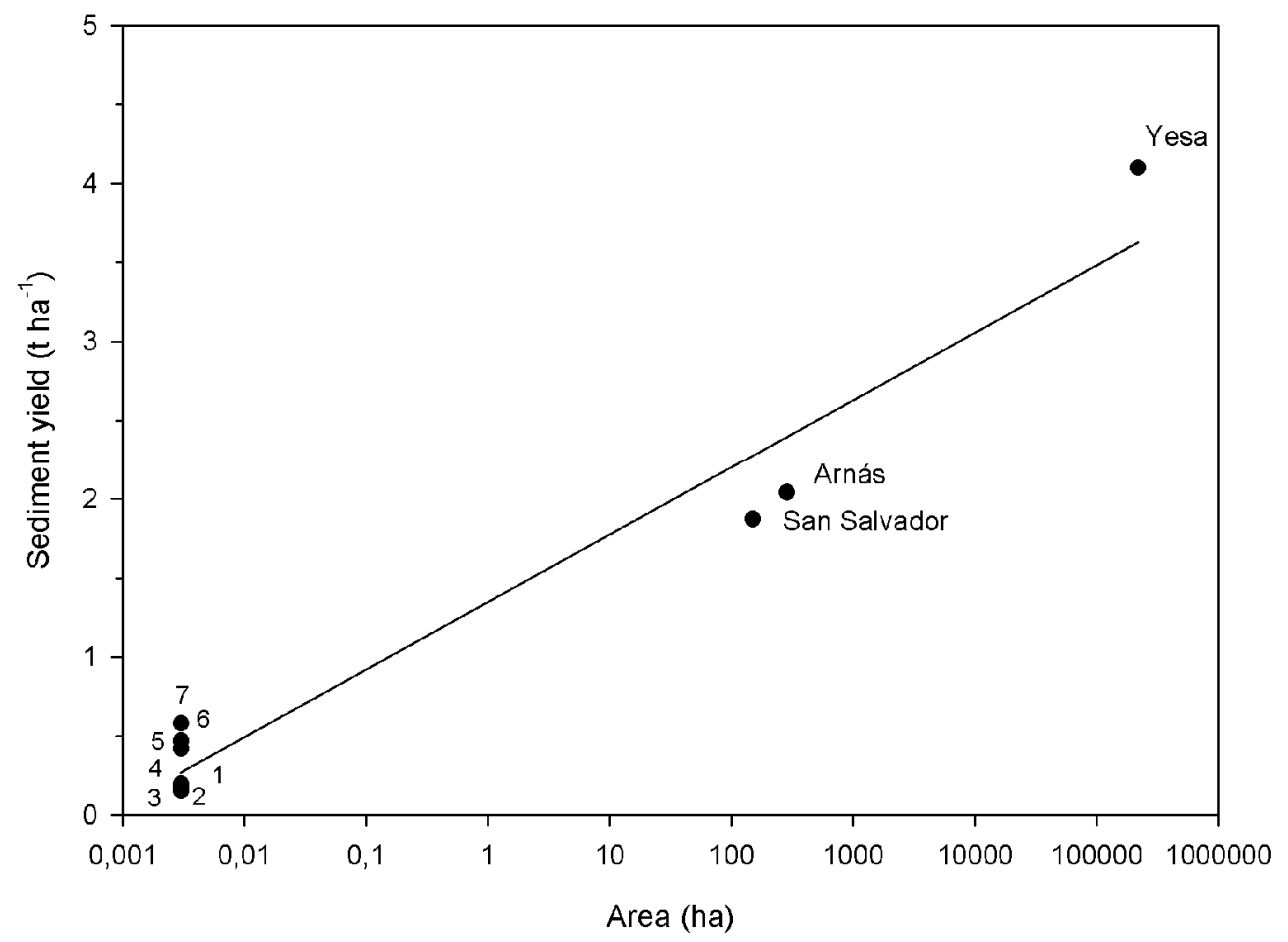

Figure 2. Relationship between catchment area and sediment delivery in the Central Spanish Pyrenees. 17: experimental plots in the Aísa Valley Experimental Station. In contradiction with the general law, results from the Central Spanish Pyrenees show a positive relationship between sediment delivery and the size of the catchment. 


\section{EROSION AND SEDIMENT TRANSPORT IN MEDITERRANEAN MOUNTAIN BASINS: MOST RELEVANT RESULTS FROM OBSERVATIONAL RESEARCH IN THE CENTRAL PYRENEES}

Experimental catchments have been considered, in general, as the most adequate approach to study runoff generation, soil erosion and sediment transport (Walling, 1991). The catchments are usually chosen to be homogeneous in lithology, topography and plant cover and have a relatively small size, and all this factors favor the control of the main processes acting in the catchment. The catchments allow us to study the hydrological response during individual rainstorms and over long periods of time, the areas of active erosion, the connectivity between sediment sources and channels, and the role of different processes, such as the partitioning of precipitation between interception, infiltration and runoff due to plant cover. Two main research questions are the consequences on the hydrological and sediment behavior of changes in the climatic conditions and on the land use/cover. Mediterranean mountain areas are particularly sensitive to these changes due to: (i) a process of farmland abandonment after centuries of cultivation of south-facing slopes and the consequent conversion to scrubland and forests; and (ii) new scenarios of climate change, that affect southern Europe and, in general, all the mountains in the world, with a particular intensity (Beniston, 2003). For this reason, detailed studies in catchments with different plant covers and land use/cover of paramount importance to compare the hydrological responses at various temporal scales (from daily events to long-term average values). This information is determinant to validate hydrological models and to forecast future trends on water resources and sediment transport under different environmental scenarios.

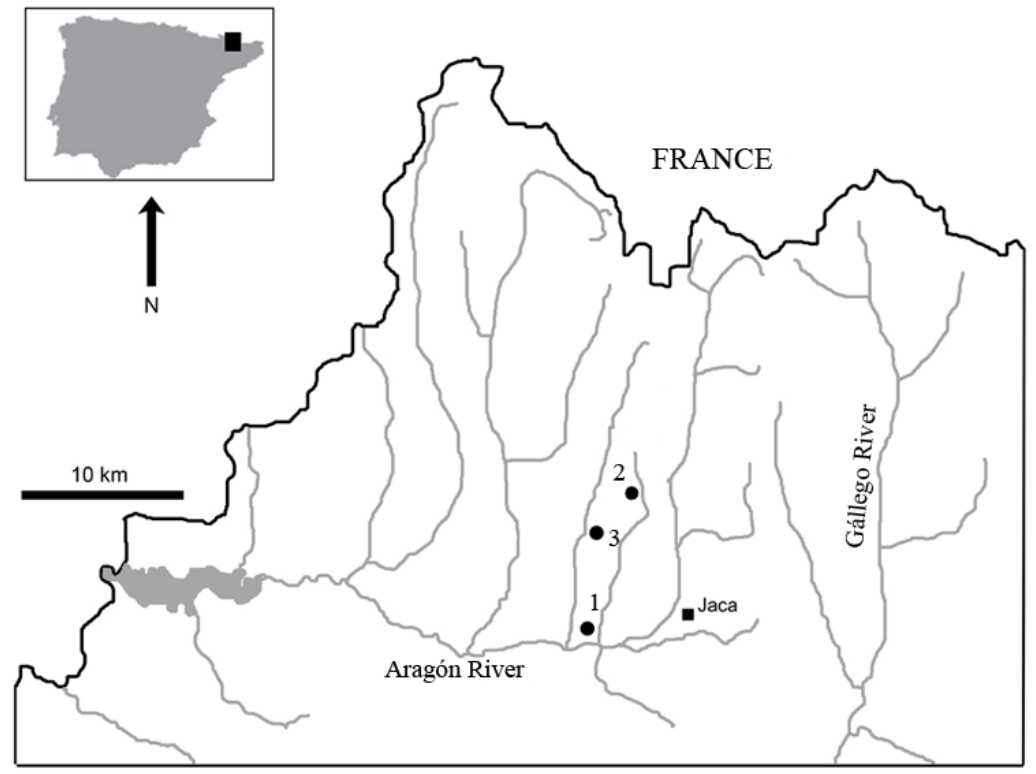

Figure 3. Location of the three experimental catchments within the Yesa reservoir catchment (upper Aragón River). Araguás (1), Arnás (2), San Salvador (3).

The Department of Geo-Environmental Processes and Global Change (Instituto Pirenaico de Ecología, CSIC) maintains a experimental station in the central Pyrenees composed by three monitored catchments. They are located in a middle mountain area, within a distance of less than $8 \mathrm{~km}$, which ensures the same precipitation characteristics (Figure 3). Each catchment is characterized by different plant cover and lithology. The San Salvador catchment (92 ha) is a tributary of the Estarrún River, with flysch bedrock, composed of thin beds of alternating sandstones and marls. The outlet is located at $810 \mathrm{~m}$, and the highest point at $1330 \mathrm{~m}$. The catchment is covered by dense forest of Pinus sylvestris, Fagus sylvatica and Quercus gr. faginea. Soils are relatively deep and well preserved. The Arnás catchment (284 ha) is a west-east oriented tributary of the Lubierre River. The substratum is also Eocene flysch. The north-facing slope shows steeper slopes, a relatively open shrub cover and thin soils, with some sectors affected by 
sheet-wash erosion. The south-facing slope has gentler slopes and deep soils, and is densely covered by shrubs and patches of forest. The outlet is located at $900 \mathrm{~m}$ and the highest part at $1330 \mathrm{~m}$. The whole catchment was cultivated until the middle of the 20th Century with cereal crops in non-terraced fields. Since then, the catchment was abandoned and affected by a process of natural plant colonization. The Araguás catchment ( $45 \mathrm{ha}$ ) is a tributary of the Lubierre River. The outlet is located at $780 \mathrm{~m}$ and the highest point is at $1105 \mathrm{~m}$. Bedrock is Eocene marl in the lower part, and flysch in the upper zone. The main characteristic is the presence of a dense network of badlands in which small mudflows, gullying, rilling and sheet wash erosion prevail. The average annual precipitation is about $800 \mathrm{~mm}$ in the three catchments, though a remarkable inter-annual variability exists.

The three catchments are equipped with automatic weather and gauging stations which allow to monitor several climatic parameters as well as the discharge - by an ultra-sound sensor —and suspended sediment concentration - thanks to a turbidimeter and an automatic water-sampler. Besides, other instruments were installed: Seven and three piezometers respectively in Arnás and San Salvador to continuously record the height of the water table; at least two more pluviometers in each catchment to control the spatial variability of the rainfall; three plots to measure rainfall interception under forest cover (pine, beech-tree and oak) in San Salvador; and temperature sensors at different depths of the regolith in Araguás. A database was elaborated with series of precipitation, discharge and suspended sediment concentration, with a time resolution of five minutes.

The most relevant results obtained up to now are summarized as an example of the information supplied by the catchment-scale approach. The main question that this experimental setting tries to answer is how land cover influences runoff and flood generation, the seasonality of floods and the spatial and temporal variability of sediment transport. It is interesting to note that, given a similar precipitation and almost similar topographic characteristics for the three catchments, the differences in runoff and sediment transport can be attributed to the differences in plant cover.

A major hydrological difference refers to the runoff coefficient, for which a clear decrease is observed as plant cover density increases (Figure 4). The overall runoff coefficient is $69 \%$ in the badland catchment (Araguás), followed by the old cultivated catchment (Arnás, 25\%) and the forest catchment (San Salvador, 11\%). Evapotranspiration is, obviously, the main factor explaining these differences. Thus, for a six-month period in 2006, interception under pine, beech tree and oak was 15, 19 and $16 \%$ in average respectively. In the case of beech tree with shrubs, interception reached $27 \%$ of the rainfall.

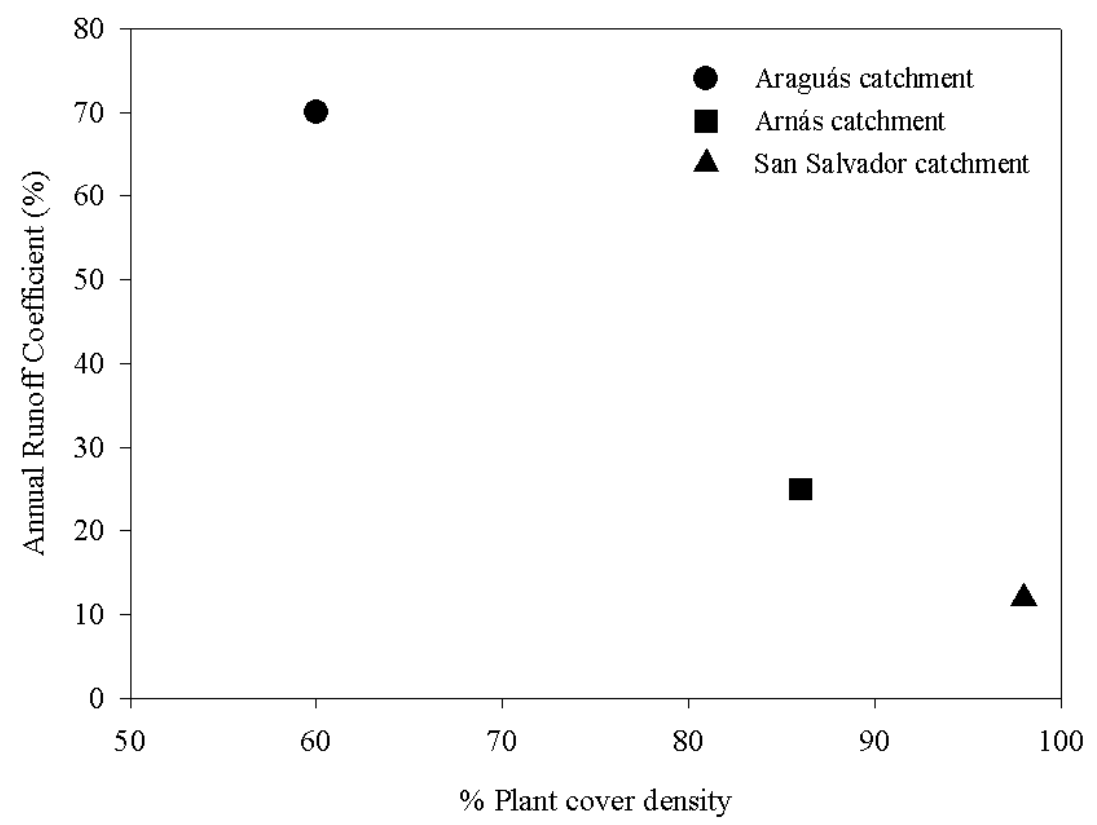

Figure 4. Relationship between plant cover density and runoff coefficient for the three experimental catchments, illustrating the increase in runoff production as the vegetation cover decreases. 

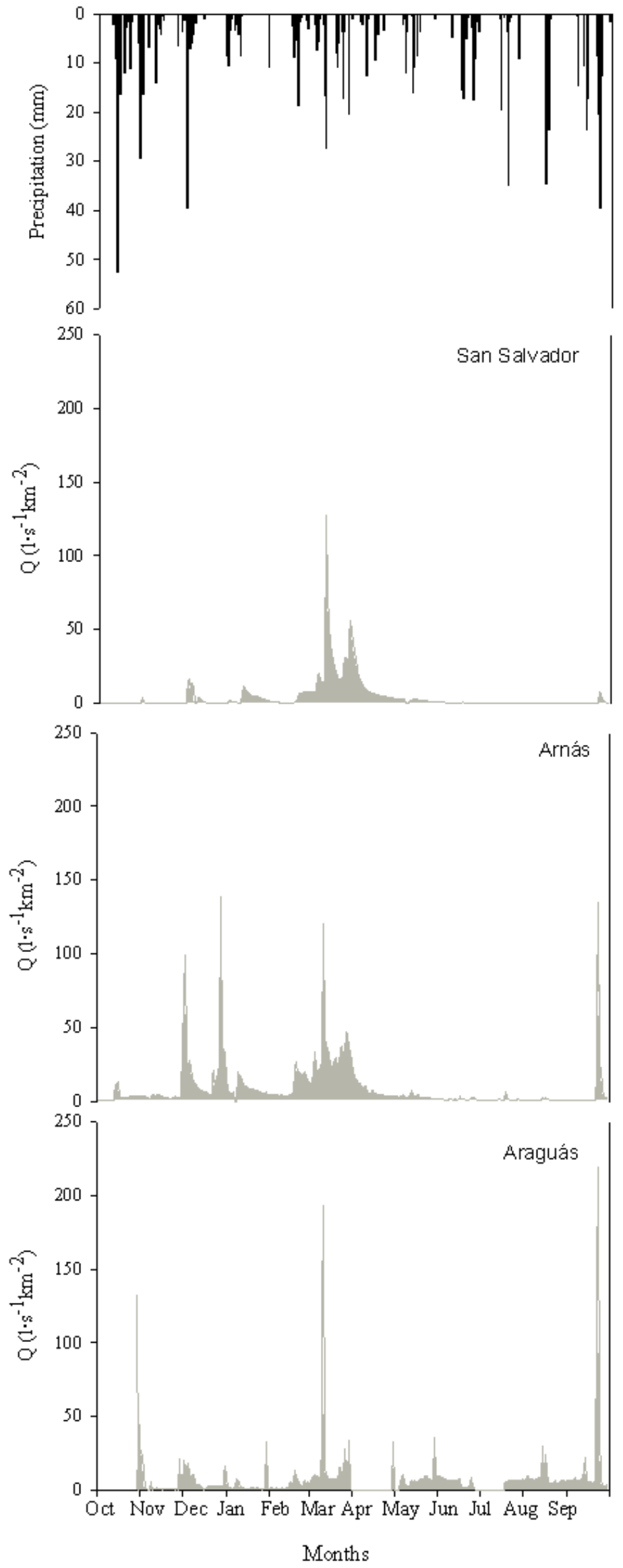

Figure 5. Hydrological response (water discharge) in the San Salvador, Arnás and Araguás catchments during one year. The input precipitation was roughly the same, so it is represented only once. 
The relationship between precipitation and discharge at event scale also shows big differences between the catchments. No good correlation was found between both variables in San Salvador catchment $(\mathrm{r} 2=0.047)$, in which the hydrological response shows an extreme variability scarcely related to the volume of the rainstorm. In Arnás catchment, the variability is also high, although in general the peakflow increases as the rainstorm event does $(\mathrm{r} 2=0.50)$. In Araguás the correlation is very high, particularly in the case of rainfalls over $10 \mathrm{~mm}(\mathrm{r} 2=0.84)$, in such a manner that the characteristics of the rainstorm event explains a large proportion of the variability of the hydrological response.

The intensity of the response during the year also varies greatly between the catchments (Figure 5). Araguás reacts very fast to each rainstorm event, with flash floods characterized by steep rising and recessing limbs and narrow peak flows. Arnás also reacts with frequent floods, although the intensity of the response is lower particularly in autumn, when the soils in the catchment are still recovering from the exhaustion of the summer. In San Salvador there are few floods, in general of low intensity, except in spring when they can be of similar importance than those of Arnás. In fact, during the 2005-06 hydrological year, which can be defined as "dry", Araguás recorded 44 floods, Arnás 12 and San Salvador only six. Remarkable differences in the timing of the floods are also evident. In Araguás floods are possible in any season of the year, even in summer and autumn; in Arnás floods tend to be relatively moderate during the autumn, except during very intense rainstorms, they are also and of moderate size in winter, and very intense in spring, whereas no floods are recorded in summer; in San Salvador, the only season with intense floods is the spring, and only small and infrequent hydrological reactions are observed in autumn and winter.

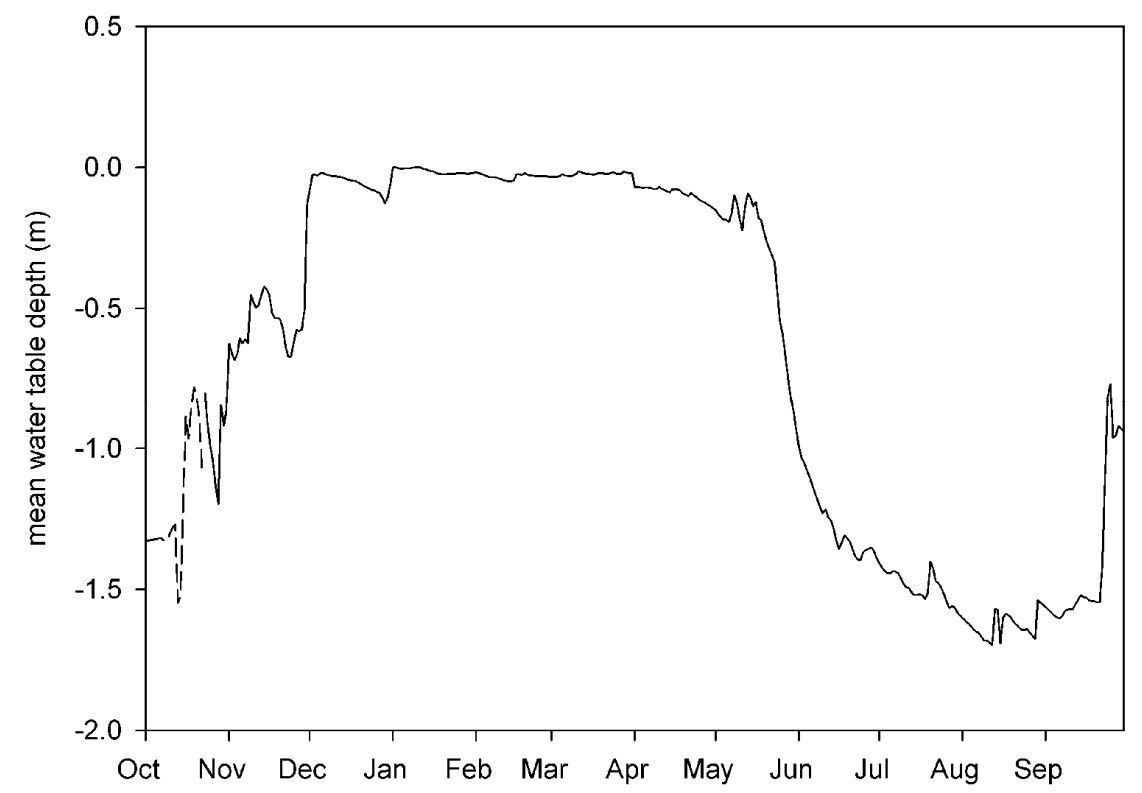

Figure 6. Temporal variation of the water table depth and runoff generation during one year in the San Salvador catchment.

This demonstrates that plant cover is able to change not only the magnitude and frequency of floods but also their seasonal distribution, and it is a key aspect to understand the hydrological functioning of the catchments. In the case of Araguás, the hydrological pattern is very simple: it is ready to produce a flood at any moment of the year given the almost total absence of soil and the impervious behavior of the marl. Thus, the occurrence of floods in Araguás is parallel to the occurrence of rainstorms. But, what is the difference between Arnás and San Salvador? Information on the groundwater table (Figure 6) shows that in San Salvador runoff in the main channel is only possible when the water table is close to the surface, and this tends to occur in spring. This implies that overland flow is caused by saturation excess flow, and it is the reason why the rest of the year runoff generation is exceptional (Serrano-Muela et al., in press). In Arnás, the 
water table has also a seasonal behavior related to the evolution of precipitation and temperature (Figure 7). After the summer drought, a recovery period is observed during the autumn in which the water table shows a constant rising; a stable period occurs from December to April, when the water table is close to the surface; and a recession period occurs in late spring and summer, when evapotranspiration exhausts progressively the water reserves. Nevertheless, floods, even of limited magnitude, are relatively frequent in autumn and winter. This is only possible taking into account the existence of relatively small sheet-wash erosion areas close to the channel, which yield overland flow with any rainfall intensity and volume. Then, the Arnás catchment produces small floods when the catchment is dry or in intermediate periods, and only small impervious areas contribute runoff, and large floods when it is wet and there is an expansion of the contributing areas. The hydrological results presented so far explain the differences in sediment transport. Major differences exist in the composition of the sediment exported from each catchment. In San Salvador most of the sediment exported is in the form of solutes (73.5\%), because water circulates preferably within the soil, and only $26.5 \%$ is exported as suspended sediment. No bed load has been recorded. In Arnás, suspended sediment prevails (46\% of total), followed by solutes (34\%) and bed load (about 20\%). This is an indicator that overland flow and soil erosion are active processes in Arnás, at least in some areas which have good conection with the channel or within the channel itself. In the case of Araguás, there are no records about the proportion of each type of sediment yet, though suspended sediment ought to be predominant since sediment sources are mostly bare marls in badlands. The maximum values of suspended sediment concentration recorded in each catchment are a good element for comparison: $1.9 \mathrm{~g} \mathrm{~L}-1$ in San Salvador, 10 g L-1 in Arnás and more than 500 g L-1 in Araguás, with many floods recording more than $100 \mathrm{~g} \mathrm{~L}-1$. With these values and those from runoff coefficients it is evident that the sediment yield per hectare is several orders of magnitude higher in Araguás than in Arnás and even more than in San Salvador. One more time, plant cover differences are the best explaining factor.
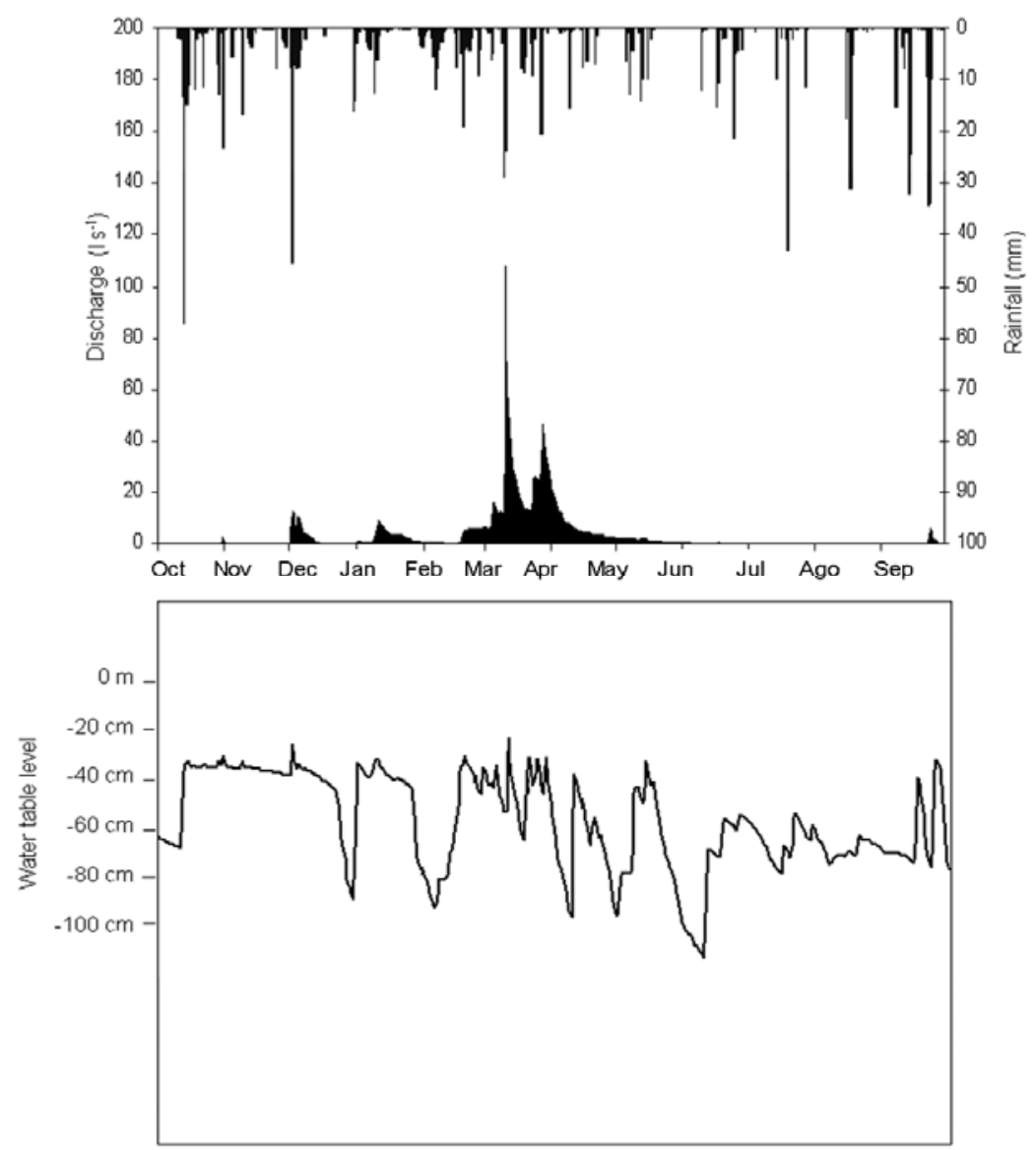

Figure 7. Temporal variation of the water table depth during one year in the Arnás catchment. 


\section{THE LINK BETWEEN EMPIRICAL STUDIES AND SIMULATION MODELS}

Erosion and sediment transport simulation models have experienced vast improvements in the last two decades, in parallel with the increase in computing power. Simulation models are attractive not only to the basic scientists who seek a convenient tool to test their ideas about the interplay of different erosion processes, but also to the applied researchers and practitioners due to their predictive and scenario testing capabilities.

Catchment stakeholders and decision makers need spatially distributed information on erosion and deposition rates as well as estimations of the water and sediment discharge from individual catchments. This information is preferably required at an event temporal scale, which allows reflecting the spatial pattern and timing of erosion and sediment transport processes in response to particular events. Current computation capabilities make it possible, from event based models, to conduct long simulations and derive long term average erosion and sediment export values.

Even if we restrict ourselves to spatially distributed, event based models, many candidate models exist which differ in the processes they incorporate and the manner these processes are treated, their spatial and temporal scales, complexity, input needs, etc. This makes choosing a model a difficult task, which depends very much on what are the main questions the model user wants to get an answer to. This requires at least a basic background on the subject of computer modeling, and that is something which model users often lack; hence, it is not infrequent to see mistaken model choices which lead to unsound results.

A large portion of the sediment budgets at catchment scale are based on field determined erosion and deposition rates, or on the use of empirically derived relationships. The use of processbased models, on the contrary, is still a minority. This is due to a combination of factors, and some of which are discussed in the next paragraphs.

Some of the difficulties of building good process-based simulation models at catchment scale arise obviously from the natural complexity of the system being modeled. As it has been shown before, several erosion and sediment transport processes interplay at different spatial and temporal domains, and with differences of several orders of magnitude. Although we have achieved good understanding of many erosion processes separately, an effort has still to be done to fully understand and incorporate into the models the interrelation between different processes. For example, there is a limited knowledge about the role of sediment sinks in the spatial connectivity of the erosion processes: in the plot domain, sediment trapping in small depressions which are usually finer than the resolution of digital terrain models - surface roughness; in the hillslope domain, sediment retention due to changes in the vegetal cover, in small concavities or in the bottom part of the slope; in the catchment domain, importance of stream erosion and deposition processes. In all different domains, there is a need to characterize these sediment storages, determining their importance and the mean residence time of the sediment.

Probably as a response to this natural complexity, models have grown very complex too. In most cases, simulation models are tested in small, controlled and data intensive experimental catchments, but they show big problems when applied to spatially larger, data scarce environments. Complex models can better represent a complex reality, but this often at the expense of becoming more prone to error propagation. Each new parameter in a model comes in association with some level of uncertainty, and this uncertainty is usually magnified in the model's results. In simple words, more complex does not always mean more accurate or less uncertain, these depend very much on the particular case of study.

This leads us to the problem of data availability. Process-based models often require large amounts of input data. Very often this data does not exist for a particular area, and need to be generated. In many cases this data is inferred from another auxiliary variable, such as the topography or the vegetation cover, resulting in an apparently good estimation in terms of spatial resolution, but with a high level of uncertainty. In other cases a field sampling campaign is undertaken, but in general only a few samples can be analyzed which allow for a general picture of the average values of the model's parameters at some characteristic areas, but do not give an adequate description of the spatial variability of the parameter. Spatial variability can be very large for some parameters which are of great importance to erosion models-such as the soil properties-, and this variability needs to be accounted for in the model. Usually, the implicit assumptions made to provide a spatial representation of the input parameters are not recognized, 
resulting in an important underestimation of the uncertainty introduced in the simulations, and leading ultimately to frustrating results.

\section{CONCLUSIONS}

Compared to natural climatic variability, plant cover and land use explain a large part of the hydrological and erosive variability in Mediterranean mountain areas. However, we need to improve our understanding of the balance between the climatic and land cover drivers, since the quantity and quality of water resources in the Mediterranean region mainly depends on mountain areas. We know that abrupt plant cover changes occurred in short periods in the past. In the case of the Pyrenees strong population pressure, overgrazing, farming in steep slopes and frequent man-induced fires for centuries resulted in landsliding, flooding and active erosion processes which caused soil degradation in many hillslopes, and the development of braided channels in most of rivers (Beguería et al., 2006). However, throughout the 20th century a rapid process of depopulation and farmland abandonment occurred, and hence the old fields and grazed areas were progressively colonized by scrubland and forests. These changes in plant cover resulted in a shrinkage of sediment sources (García-Ruiz and Valero-Garcés, 1998), a reduction of flooding (López-Moreno et al., 2006) and a negative temporal trend in stream flow (Beguería et al., 2003). Being able to get operative estimations of the consequences of possible future climate and land use changes is of paramount importance everywhere and specially in the Mediterranean mountain context. This will help to plan the management of reservoirs and of different water uses (agriculture, industrial or domestic uses, environmental flow, etc).

The results obtained from the experimental catchments in the Pyrenees confirm all these trends and allow us to understand the leading processes in catchments of different characteristics, such as the seasonal fluctuations of water table, the rate of regolith weathering, the rainfall interception under forest and scrubland cover, the location of runoff and sediment sources and the temporal variability of contributing areas. This is basic information useful to model makers as well as to basic scientists, and the effort should be maintained to include the new problems that arise from the research, such as the role of the sediment sinks in the spatial connectivity of the erosion processes.

Research on simulation models should be maintained at the same level, too. The experience won from observational studies and from using complex partial models should be used to determine which are the main processes leading erosion and sediment transport at the different scales. This knowledge should be used to build a new generation of models, characterized by their robustness and their ability to work in data scarce environments. Parameter uncertainty and error propagation is another feature that must be included explicitly in the models, as a way to make the model users aware of its importance. In any case, the usefulness of new simulation models will depend strongly on their ability to integrate processes operating at different spatial and temporal scales, from the event/plot to the long term/catchment.

\section{REFERENCES}

Almorox, J., De Antonio, R., Saa, A., Díaz, M.C. \& Gascó, J.M. 1994. Métodos de estima de la erosión hídrica. Madrid: Editorial Agrícola Española.

Beguería, S. 2005. Erosión y fuentes de sedimento en la cuenca del embalse de Yesa (Pirineo Occidental): Ensayo de una metodología basada en teledetección y análisis SIG. Zaragoza: Instituto Pirenaico de Ecología.

Beniston, M. 2003. Climatic change in mountain regions: a review of possible impacts. Climatic Change, 59: 5-31.

Beguería, S., López-Moreno, J.I., Gómez-Villar, A., Rubio, V., Lana-Renault, N. \& GarcíaRuiz, J.M. 2006. Fluvial adjustments to soil erosion and plant cover changes in the Central Spanish Pyrenees. Geografiska Annaler, 88A(3): 177-186.

García-Ruiz, J.M. \& Valero-Garcés, B. 1998. Historical geomorphic processes and human activities in the Central Spanish Pyrenees. Mountain Research and Development, 18(4): 309320 
García-Ruiz, J.M., Lana-Renault, N., Beguería, S., Valero-Garcés, B., Lasanta, T., Arnáez, J., López-Moreno, J.I., Regüés, D. \& Martí-Bono, C. 2004. Temporal and spatial interactions of slope and catchment processes in the Central Spanish Pyrenees. IAHS Publ., 288: 21-28.

Gómez-Villar, A., Álvarez-Martínez, J. \& García-Ruiz, J.M. (2006): Factors influencing the presence or absence of tributary-junction fans in the Iberian Range, Spain. Geomorphology, 81: $252-264$.

González Sampériz, P. \& Sopena, M.C. 2002. Recent Holocene Palaeoenvironmental evolution in the Central Ebro Basin (NE Spain). Quaternary International, 93-94: 177-190.

Kosmas, C., Danalatos, N., Cammeraat, L.H., Chabart, M., Diamantopoulos, J., Farand, R., Gutiérrez, L., Jacob, A., Marques, H., Martínez-Fernández, J., Mizara, A., Moustakas, N., Nicolau, J.M., Oliveros, C., Pinna, G., Puddu, R., Puidefábregas, J., Roxo, M., Simao, A., Stamou, G., Tomasi, N., Usai, D. \& Vacca, A. 1997. The effect of land use and soil erosionj rates under Mediterranean conditions. Catena, 29: 45-59.

Puigdefábregas, J. \& Mendizábal, T. 1995. Desertification and migrations. Logroño: Geoforma Ediciones.

Montserrat, J. 1992. Evolución glaciar y postglaciar del clima y la vegetación en la vertiente sur del Pirineo: Estudio palinológico. Zaragoza: Instituto Pirenaico de Ecología.

Nadal-Romero, E., Regüés, D., Martí-Bono, C. and Serrano-Muela, P. 2007. Badland dynamics in the Central Pyrenees: temporal and spatial patterns of weathering processes. Earth Surface Processes and Landforms, 32 (6): 888-904.

Peña, J.L., Echeverría, M.T., Petit-Maire, N. \& Lafont, R. 1993. Cronología e interpretación de las acumulaciones holocenas de la val de las Lenas (Depresión del Ebro, Zaragoza). Geographicalia, 30: 321-332.

Poesen, J.W.A. \& Hooke, J.M. 1997. Erosion, flooding and channel management in Mediterranean environments of southern Europe. Progress in Physical Geography, 21 (2): 157-199.

Regüés, D. \& Gallart, F. 2004. Seasonal patterns of runoff and erosion responses to simulated rainfall in a badland area in Mediterranean mountain conditions (Vallcebre, Southeastern Pyrenees). Earth Surface Processes and Landforms, 29: 755-767.

Serrano-Muela, M.P., Lana-Renault, N., Nadal-Romero, E., Regüés, D., Latron, J., Martí-Bono, C. \& García-Ruiz, J.M. In press. Forests and water resources in Mediterranean mountains: The case of the Spanish Pyrenees. Mountain Research and Development.

Walling, D.E. 1991. Drainage basin studies. In O. Slaymaker (ed), Field experiments and measurement programs in Geomorphology, Rotterdam: Balkema.

White, S., García-Ruiz, J.M., Martí-Bono, C., Valero, B., Errea, M.P. \& Gómez-Villar, A. 1997. The 1996 Biescas campsite disaster in the Central Spanish Pyrenees, and its temporal and spatial context. Hydrological Processes, 11: 1797-1812.

Yaalon, D.H. 1997. Soils in the Mediterranean region: what makes them different? Catena, 28:157-169. 